\title{
Peripheral Cytokines and Chemokines in Alzheimer's Disease
}

\author{
Kang Soo Lee $e^{a, b}$ Ji Hyung Chung ${ }^{c, d}$ Tae Kyou Choi ${ }^{a}$ Shin Young Suh ${ }^{a}$ \\ Byoung Hoon $\mathrm{Oh}^{b}$ Chang Hyung Hong ${ }^{\mathrm{e}, \mathrm{f}}$ \\ ${ }^{a}$ Department of Psychiatry, CHA University, Bundang Cha Medical Center, Seongnam, ${ }^{b}$ Department of Medicine, \\ Graduate School, Yonsei University, ' Yonsei Integrative Research Institute for Cerebral and Cardiovascular \\ Diseases, and d Yonsei University Health System, Seoul, ${ }^{e}$ Department of Psychiatry, Ajou University School of \\ Medicine, and ${ }^{\mathrm{f}}$ Memory Impairment Center, Ajou University Hospital, Suwon, Korea
}

\section{Key Words}

Alzheimer's disease • Inflammation • Cytokines •

Chemokines $\cdot$ Biomarkers

\begin{abstract}
A chronic inflammatory process has been implicated in the neuropathology of Alzheimer's disease (AD). The present review focuses on the current knowledge of circulating serum and plasma biomarkers of $A D$ that are linked to inflammatory reactions. There is abundant evidence that inflammatory mechanisms within the central nervous system contribute to cognitive impairment via cytokine-mediated interactions between neurons and glial cells. Interleukins 1 , $4,6,10,12,16$, and 18, tumour necrosis factor, and several chemokines have been suggested as biomarkers of $A D$. Nonetheless, data on circulating cytokine levels are somewhat inconsistent with regard to peripheral cytokine dysregulation in $A D$. In summary, definite statements concerning differences in inflammatory biomarkers between controls and $A D$ patients will require the use of sensitive multiplex assays in large patient groups in conjunction with measures of disease severity.

Copyright $\odot 2009$ S. Karger AG, Basel
\end{abstract}

\section{Introduction}

A chronic inflammatory process has been implicated in the neuropathology of Alzheimer's disease (AD), which is the most common form of dementia in the elderly [1-4]. The inflammatory components in $\mathrm{AD}$ include microglia and astrocytes, the complement system, and various inflammatory mediators (including cytokines and chemokines). Most AD research has concentrated on the activity of neuronal cells, but increasing evidence suggests a major role for glial cells and changes in their function in the pathway leading to neuronal degeneration. A current hypothesis is that an extracellular insult to neurons could trigger the production of inflammatory cytokines by astrocytes and microglia [4]. In this context, it has been reported that cytokines secreted by microglial cells, astrocytes, and/or neurons may induce the synthesis of certain acute-phase proteins, including the amyloid precursor protein A $\beta P P$ [5]. Conversely, amyloid- $\beta$ peptide $(A \beta)$ itself has been shown to induce the expression of interleukin (IL)-1 $\beta$, tumour necrosis factor (TNF)- $\alpha$, and IL- 6 in astrocytes and microglia in culture [6]. Thus, a direct correlation has been established between $A \beta$-induced neurotoxicity in neurodegenerative conditions and cytokine production. 
Cerebrospinal fluid (CSF) closely reflects the composition of the brain extracellular space and is likely to have the highest yield of biomarkers for the evaluation of dementia [7]. Nonetheless, CSF is not routinely collected for the evaluation of $\mathrm{AD}$, and lumbar puncture is not a widespread procedure in primary care, psychiatric practice, or geriatric facilities that care for $\mathrm{AD}$ patients. Therefore, blood biomarker molecules would be more widely applicable and would reduce the need for invasive, expensive, and time-consuming testing. The physiology of the blood-brain barrier may limit potential diagnostic biomarkers to small molecules, lipophilic molecules, or molecules with specific transporters. Brain proteins and metabolites that pass into the plasma become markedly diluted into a biochemically complex medium. The present review focuses on the current knowledge of circulating serum and plasma biomarkers for $\mathrm{AD}$ that are linked to inflammatory reactions. The information available indicates that the effects of cytokines and other brain neuroimmune modulators oscillate between the opposing actions of neuroprotection and neurodegeneration. In this context, we analyse here some of these major cytokines and chemokines.

\section{Peripheral Cytokines and Chemokines in AD}

\section{Cytokines}

\section{Interleukin Family}

Interleukin-1

IL- 1 is associated with $A \beta$ in senile plaques and increases the synthesis and translation of A $\beta P P$ mRNA, the processing of which produces $A \beta$. Most studies that have investigated serum or plasma levels of IL-1 $\beta$ have not detected any difference between $\mathrm{AD}$ patients and controls [8-12]. However, a study of 145 AD patients and 51 controls showed higher serum concentrations of IL-1 $\beta$ in AD patients than in controls [13]. This discrepancy could be explained by the low serum levels of IL- $1 \beta$ found in the normal controls, in addition to the low sensitivity of the ELISA systems used. For example, plasma IL- $1 \beta$ could be detected in only $13 \%$ of the patients and in $2 \%$ of the controls [13]. Similarly, in another study [11], most samples tested had IL-1 $\beta$ levels below the detection limit of the ELISA used $(10 \mathrm{pg} / \mathrm{ml})$. Thus, it is not possible to measure serum IL-1 $\beta$ levels in most AD patients, which may explain why differences in mean concentrations between $\mathrm{AD}$ patients and controls can only be detected when large sample sizes are used [14].
Interleukin- 4

IL-4 is a potent anti-inflammatory cytokine that is thought to modulate the neuroinflammatory process in $\mathrm{AD}$ by antagonising the proinflammatory activity of IL$1 \beta$. IL-4 is expressed in normal brains [15] and appears to be affected by cholinesterase inhibitors [16]. Two studies found that IL-4 levels in peripheral monocytes of AD patients treated with donepezil were significantly higher than the levels in untreated AD patients and non-demented controls $[17,18]$. Furthermore, IL-1 $\beta$ levels were significantly lower in donepezil-treated AD patients [17], and these changes were independent of age, gender, and other comorbidities [18]. These findings indicate that cholinesterase inhibitors may alter the progression of $\mathrm{AD}$ by modifying IL-1-induced inflammation through IL-4.

\section{Interleukin-6}

IL-6, a cytokine that mediates immune responses and inflammatory reactions affecting CNS cell growth and differentiation, is markedly induced under pathological conditions. Serum IL-6 levels correlated with IL-6 levels in matched CSF samples from probable AD subjects [19] and soluble CSF IL-6 receptor levels, which reflect changes in IL-6 signalling, were reduced in AD patients, suggesting perhaps a compensatory downregulation of aberrant IL-6 activation [20]. Several studies have reported increased levels of IL- 6 in the serum or plasma of AD patients compared with controls [12, 13, 21-23], whereas other studies have found no difference $[10,24,25]$.

Interleukin-10

IL-10 is a potent anti-inflammatory cytokine in the CNS that may function to reduce inflammation during AD. IL-10 mRNA is expressed in the normal brain, but few neuropathological data exist for IL-10 changes in the $\mathrm{AD}$ brain [15]. In the periphery, IL-10 levels are unaltered in blood cells of AD patients following lipopolysaccharide stimulation $[26,27]$, as well as in the serum of $\mathrm{AD}$ patients [28-30]. However, it has been reported that patients with dementia have higher mean levels of IL-10 [31, 32 ], and there is an increase in brain IL-10 in neurological diseases, including AD [33]. The decrease in IL-10 production in peripheral blood mononuclear cells (PBMCs) in the presence of $A \beta(1-40)$ is not dependent on the severity of the disease, indicating that both the fragment and IL-10 may play potential roles in the pathogenesis of AD [34]. Low levels of IL-10 may be associated indirectly with a nonspecific and secondary inflammatory status. In fact, the function of IL-10 is to limit inflammation by reducing the synthesis of proinflammatory cytokines, 
suppressing cytokine receptor expression and inhibiting markers of activation. Given that data show a decrease in IL-10 production from PBMCs in AD patients only after stimulation with $A \beta(1-40)$, we can hypothesise a reduction in suppression that is related specifically to this $A \beta$ fragment [34].

\section{Interleukin-12}

IL-12 is a heterodimeric cytokine produced by activated blood monocytes, macrophages, and glial cells that promotes the acquisition of a T helper (Th) 1 cytokine profile. Intrathecal and serum levels of the IL-12 p70 heterodimer have been reported to be almost undetectable in patients with $\operatorname{AD}[28,35]$. The function of IL-12, which can both promote inflammation and inhibit the pathological process, relies largely on the expression and degradation of the different component proteins. The results of one study [36] showed that IL-12 plasma levels were dependent on the severity of AD. Specifically, elevated cytokine plasma levels were observed in patients with mild and moderate $\mathrm{AD}$, whereas cytokine levels decreased in patients with severe AD.

\section{Interleukin-16}

IL-16 is a growth factor for resting CD4+ cells. IL-16 stimulates the production of IL- $1 \beta$, IL- 6 and TNF- $\alpha$, increases intracellular levels of $\mathrm{Ca}^{2+}$ and inositol 1,4,5-trisphosphate, and causes the translocation of protein kinase C - 3 crucial events required to trigger neuronal ischaemic cell death and the post-ischaemic inflammatory CNS response. One study has shown that plasma IL-16 levels are dependent on the severity of $\mathrm{AD}$, with elevated levels found in patients with mild and moderate $\mathrm{AD}$, but reduced levels seen in patients with severe $\mathrm{AD}$ [36].

\section{Interleukin-18}

IL-18 is a member of the IL-1 cytokine family that induces the production of Th1 cytokines. IL-18 plasma levels were significantly elevated in $\mathrm{AD}$ patients and were correlated with the severity of the disease indicating an emerging role of IL-18 in the pathophysiological process of $\mathrm{AD}$ [36]. Plasma levels of IL-18 are dependent on the degree of the disease, with higher levels seen in patients with mild and moderate $\mathrm{AD}$ and lower levels seen in patients with severe $\mathrm{AD}$ [36].

\section{Tumour Necrosis Factor Family}

TNF- $\alpha$ seems to be a nonspecific but significant factor in the development of several psychiatric diseases, including depression and dementia. In the pathogenesis of
$\mathrm{AD}, \mathrm{TNF}-\alpha$ is produced by activated microglia, mainly in response to the $A \beta(1-40)$ and $A \beta(1-42)$ peptides as well as to oxidative stress. There is consensus that serum concentrations of TNF- $\alpha$ and the soluble TNF- $\alpha$ receptor increase with age $[37,38]$. However, results regarding concentrations of TNF- $\alpha$ in the serum of patients with $\mathrm{AD}$ are not consistent. It has been reported that TNF- $\alpha$ concentrations are lower in serum from demented patients (multi-infarct dementia and AD) compared with healthy controls $[39,40]$. In addition, serum TNF- $\alpha$ levels are significantly lower in patients with mild-to-moderate $\mathrm{AD}$ compared with patients with severe $\mathrm{AD}$ and vascular dementia, suggesting a difference in the cytokine profile at different stages of $\mathrm{AD}$ as well as for different types of dementia [40]. In contrast, higher serum TNF- $\alpha$ concentrations have been reported for AD patients [37, 41-43], and several other studies have reported no significant differences between $\mathrm{AD}$ patients and controls [10, 12, 14, 25]. Furthermore, AD patients have lower serum concentrations of the neuroprotective factor, such as an insulinlike growth factor, the concentration of which is negatively correlated with TNF- $\alpha$ levels.

A neuroprotective role for TNF- $\alpha$ against neurodegeneration by $A \beta(1-42)$ and oxidative stress in hippocampal neurons has been found. TNF-related apoptosisinducing ligand (TRAIL) is a type II integral membrane protein that belongs to the TNF superfamily. TRAIL is normally expressed in macrophages and can be induced in neurons by $A \beta$ and in astrocytes following stimulation with cytokines. In addition, TRAIL is specifically expressed in the brain of $\mathrm{AD}$ patients and is completely absent in the brain of non-demented patients.

\section{Transforming Growth Factor- $\beta$}

Transforming growth factor (TGF)- $\beta$ is a cytokine with inhibitory functions in several immunological processes, including inflammation and cellular immune responses. The role of this cytokine in neurodegenerative disorders remains controversial. For example, in AD, TGF- $\beta 1$ has been reported to stimulate astrocytes and thus to generate $A \beta(1-40)$ and $A \beta(1-42)$ peptides. TGF- $\beta$ may stimulate astrocytes to produce APP, release soluble $A P P \beta$, and then generate $A \beta$. In contrast, other studies have indicated that TGF- $\beta$ stimulates activated microglia to remove $A \beta$ protein from the brain to blood vessels. In AD patients, significantly elevated TGF- $\beta$ levels have been found in serum and in CSF when compared with patients with other forms of dementia. Again, one study has shown that plasma TGF- $\beta 1$ levels are dependent on the degree of $\mathrm{AD}$, with higher levels seen in patients with 
mild-to-moderate $\mathrm{AD}$, but lower levels seen in patients with severe $\mathrm{AD}[36]$.

\section{Chemokines}

Chemokines are a superfamily of chemotactic cytokines that are essential for the activation and migration of leukocytes in both physiological and pathological contexts.

\section{Chemokines}

Monocyte Chemotactic Protein

Monocyte chemotactic protein (MCP) is a member of the CC chemokine family that plays a significant role in inflammatory processes, including atherosclerosis and neurodegenerative disorders. Microglial cells produce MCP and stimulate astrocytes, which together participate in the degradation of $A \beta$ peptides. MCP-1 upregulation has been demonstrated in neurodegenerative diseases such as $\mathrm{AD}$ [44], and there is evidence indicating that plasma levels of MCP-1 could act as biomarkers to monitor the inflammatory process of AD [45]. MCP-1 levels are likely to be influenced by age because a correlation has been observed between age and elevated MCP-1 levels in the Japanese population [46]. Similarly, MCP-3 is the most potent chemokine capable of regulating macrophages and monocytes, which have been shown to play an important role in recruiting and maintaining the inflammatory infiltrate. MCP-3 is one of the 18 signalling proteins in blood plasma that can be used to discriminate between patients with $\mathrm{AD}$ and controls with an accuracy of almost $90 \%$ [44].

\section{Chemokines}

Interleukin-8

IL-8, a microglia-derived chemokine produced in response to proinflammatory signals such as amyloid, could be important for recruiting activated microglia into areas of the brain damaged by AD. Although IL-8 itself has not been demonstrated in the $\mathrm{AD}$ brain, immunoreactivity against IL-8 receptor $\mathrm{B}$, also known as CXCR2, has been localised to dystrophic neurites, suggesting that IL- 8 may mediate glial interactions with neurons and thereby contribute to neuronal damage. No significant differences were found in IL-8 levels between controls and patients or between patients with mild-tomoderate and severe disease [27].

Macrophage Migration Inhibitory Factor

Macrophage migration inhibitory factor (MIF) is a proinflammatory lymphokine with a broad range of im- mune and inflammatory actions. Interestingly, MIF can also bind $A \beta$ protein, which has potentially important pathophysiological implications for the accumulation of $\mathrm{A} \beta$ in the AD brain. Macrophages stimulated with MIF secrete TNF, IL-1, and IL-8, all proinflammatory cytokines that are abundant in inflammatory lesions. Thus, MIF may play a prominent role in the regulation of the inflammatory response in $\mathrm{AD}$. MIF shares many functional features with chemokines and has therefore been classified as having a chemokine-like function. One study has demonstrated that MIF levels are higher in $\mathrm{AD}$ patients than in patients without cognitive impairment [47].

Monokine Induced by $\gamma$-Interferon

Monokine induced by $\gamma$-interferon (MIG) maintains the cytokine gradient in the region of CNS inflammation. One study has demonstrated that MIG levels are higher in $\mathrm{AD}$ patients than in patients with either no or mild cognitive impairment [47]. In this study, which measured levels of both interferon-inducible protein 10 (IP-10, which is usually activated together with MIG) and MCP-1 (which, like MIG, acts on monocytes/macrophages), it was found that plasma MIG levels correlated with IP-10 levels, but not with MCP-1 levels.

\section{CX3C Chemokines}

\section{Fractalkine}

The novel CX3C chemokine fractalkine is a 373-amino acid protein that has a chemokine domain located on top of a mucin-like stalk. With regard to the role of fractalkine in $\mathrm{AD}$ pathogenesis, fractalkine loses control over microglial activation, which is considered a damaging process in $\mathrm{AD}$ pathogenesis. Recently, patients with $\mathrm{AD}$ were found to have higher plasma levels of soluble fractalkine than healthy control subjects [48]. Also, higher plasma levels of soluble fractalkine were found in patients with mild-to-moderate AD compared to patients with severe AD. That study provides preliminary evidence that soluble fractalkine is likely to play an important role in the pathogenesis of AD.

\section{Issues in Peripheral Cyto-/Chemokines of AD}

\section{Role of the Blood-Brain Barrier}

The blood-brain barrier (BBB) restricts the exchange of polar solutes, such as $A \beta$, between the brain and blood due to the presence of tight junctions between the cerebrovascular endothelial cells. The presence of the BBB 
could interfere with the movement of brain molecules to the peripheral blood, compromising the validity of these biomarkers. This is a well-known phenomenon in other types of brain damage, such as that due to trauma, in which significant gradients of some biomarkers (such as protein S-100 or enolase) have been detected between CSF and plasma.

Alternatively, AD may be associated with a more widespread immune dysregulation that is detectable in plasma. Recent studies have suggested a possible involvement of systemic cyto-/chemokines in $\mathrm{AD}$, although it is still being debated whether brain cytokine overproduction might contribute to the pool of peripheral cytokines by a spillover from the CNS or whether peripheral cytokines might affect human brain functions by crossing the BBB and interacting with the CNS. Five pathways by which cytokine signals may be relayed across the BBB have been studied: (1) cytokines are actively transported across the BBB; (2) cytokines activate peripheral vagus nerves, which in turn activate targets in the CNS; (3) cytokines leak across the $\mathrm{BBB}$ at circumventricular organs (CVOs) and activate CNS targets in the vicinity of CVOs; (4) cytokines induce the production of cytokines from cells of the $\mathrm{BBB}$, which then secret cytokines into the brain parenchyma; (5) cytokines may be carried across the BBB by infiltrating leukocytes [49].

The uptake of cytokines and chemokines by the brain might depend on a compromised $\mathrm{BBB}$, as ageing and neurodegenerative diseases are known to contribute to $\mathrm{BBB}$ impairment. Changes in BBB permeability also occur in vascular diseases, hypertension, and stroke - all of which are risk factors for $\mathrm{AD}$.

\section{Correlations between CSF and Plasma Compartments}

Few studies have investigated correlations between CSF and blood cyto-/chemokine levels in AD. One study demonstrated a strong positive correlation between CSF and plasma levels of 1-antichymotrypsin, IL-6, and MCP1 and a borderline significance for oxidised low-density lipoprotein [19]. We have summarised the results found in the literature, including information regarding cytokines and chemokines measured in the blood and CSF (table 1).

\section{Perspectives}

There is abundant evidence that inflammatory mechanisms within the CNS contribute to cognitive impairment via cytokine-mediated interactions between neu-
Table 1. Summary of concentrations of cyto-/chemokines in the blood and CSF of AD patients

\begin{tabular}{|c|c|c|}
\hline Marker & CSF level & Blood level \\
\hline \multicolumn{3}{|l|}{ Cytokine } \\
\hline IL-1 & no difference $[8,9]$ & no difference [8-12] \\
\hline & increased $[10-12,38]$ & increased [13] \\
\hline IL-4 & & increased $[16,17]$ \\
\hline \multirow[t]{2}{*}{ IL-6 } & no difference & no difference $[10,24,25]$ \\
\hline & $\begin{array}{l}{[20,22,25,35,38]} \\
\text { increased }[8,19]\end{array}$ & increased $[12,13,19,21-23]$ \\
\hline IL-10 & no difference [30] & no difference $[28-30]$ \\
\hline & & increased $[31,32]$ \\
\hline IL-12 & no difference [30] & increased [36] \\
\hline IL-16 & & increased [36] \\
\hline IL-18 & & increased [36] \\
\hline TNF & no difference $[10,38]$ & decreased $[39,40]$ \\
\hline & increased [12] & $\begin{array}{l}\text { no difference }[10,12,14,25] \\
\text { increased }[37,41-43]\end{array}$ \\
\hline TGF- $\beta$ & increased [30] & increased [36] \\
\hline \multicolumn{3}{|l|}{ Chemokine } \\
\hline MCP & no difference $[19,46]$ & increased $[19,44,45]$ \\
\hline IL-8 & & no difference [27] \\
\hline MIF & & increased [47] \\
\hline MIG & & increased [47] \\
\hline Fractalkine & & increased [48] \\
\hline
\end{tabular}

rons and glial cells. Nonetheless, data regarding circulating cytokine levels have been somewhat inconsistent in terms of peripheral cytokine dysregulation in AD. In general, cytokine actions are the result of a complex network that often involves feedback loops and cascades, with the overall response being dependent on the synergistic or antagonistic actions of the various components. As a result of their pleiotropism, it is difficult to pinpoint the specific actions of individual cytokines. In addition, although the initial events triggering the neurodegenerative processes may be different, a similar cascade of cytokine production may be initiated in response to neuronal injury. The cytokines released in the CNS may, in turn, act in a similar manner in CNS diseases, amplifying certain pathological events. Therefore, the measurement of a single cytokine does not allow us to draw any conclusions regarding disease-specific effects. The fluorescent bead-based detection assay has a clear advantage over conventional ELISA in that it can detect large numbers of analytes simultaneously; therefore, the former provides a powerful tool for profiling multiple cytokines [50].

Confounding factors in these studies of inflammatory markers include differences in plasma collection proto- 
cols, assay methodology, assay sensitivity, small sample sizes, heterogeneous patient populations, and the effects of disease severity, age, and comorbid inflammatory illness. Problems in the analysis of cytokines and chemokines include their low plasma and/or serum levels and the low sensitivity of the ELISA systems used. For example, in one study, plasma IL- 6 could be detected in only $53 \%$ of $\mathrm{AD}$ patients and in $27 \%$ of controls [13]. Another problem in studies on ILs could arise from the use of bioassays (e.g. stimulation of cultured cells by ILs) [14]. A general decline in immunological function is considered a hallmark of the ageing process. Increasing age is associated with changes in serum levels of various cytokines, although quantitative cytokine changes in healthy older people have not been demonstrated uniformly. Serum IL6 concentrations that increase with age have been reported for various healthy populations. In addition, age-related increases in TNF- $\alpha$ and TNF receptors have been demonstrated in the blood, whereas negative findings have been found when mononuclear cells were used. It is possible that the severity of the dementia also has an effect, but unfortunately not all studies measured the duration or the severity of the dementia. The low number of patients included in several studies may have also limited their ability to establish a relationship with disease severity.

In summary, definite statements regarding differences in inflammatory biomarkers between controls and $\mathrm{AD}$ patients will require the use of sensitive multiplex assays in large patient groups in conjunction with assessments of disease severity.

\section{Acknowledgements}

This study was supported by a grant from the Korea Health 21 R\&D Project of the Ministry of Health and Welfare, Republic of Korea (A050079), and sponsored by GSK Korea.

\section{References}

1 Eikelenboom P, van Gool WA: Neuroinflammatory perspectives on the two faces of Alzheimer's disease. J Neural Transm 2004; 111:281-294.

-2 Maccioni RB, Rojo LE, Fernandez JA, Kuljis RO: The role of neuroimmunomodulation in Alzheimer's disease. Ann NY Acad Sci 2009;1153:240-246.

$\checkmark 3$ Shaftel SS, Griffin WS, O'Banion MK: The role of interleukin-1 in neuroinflammation and Alzheimer disease: an evolving perspective. J Neuroinflammation 2008;5:7.

$\checkmark 4$ Rojo LE, Fernandez JA, Maccioni AA, Jimenez JM, Maccioni RB: Neuroinflammation: implications for the pathogenesis and molecular diagnosis of Alzheimer's disease. Arch Med Res 2008;39:1-16.

5 Blasko I, Veerhuis R, Stampfer-Kountchev M, Saurwein-Teissl M, Eikelenboom P, Grubeck-Loebenstein B: Costimulatory effects of interferon-gamma and interleukin-1beta or tumor necrosis factor alpha on the synthesis of Abeta1-40 and Abeta1-42 by human astrocytes. Neurobiol Dis 2000;7:682-689.

6 Gitter BD, Cox LM, Rydel RE, May PC: Amyloid beta peptide potentiates cytokine secretion by interleukin-1 beta-activated human astrocytoma cells. Proc Natl Acad Sci USA 1995;92:10738-10741.
7 Blennow K: Cerebrospinal fluid protein biomarkers for Alzheimer's disease. NeuroRx 2004; $1: 213-225$.

-8 Blum-Degen D, Muller T, Kuhn W, Gerlach M, Przuntek H, Riederer P: Interleukin-1 beta and interleukin- 6 are elevated in the cerebrospinal fluid of Alzheimer's and de novo Parkinson's disease patients. Neurosci Lett 1995;202:17-20.

-9 Cacabelos R, Barquero M, Garcia P, Alvarez XA, Varela de Seijas E: Cerebrospinal fluid interleukin-1 beta (IL-1 beta) in Alzheimer's disease and neurological disorders. Methods Find Exp Clin Pharmacol 1991;13:455-458.

-10 Lanzrein AS, Johnston CM, Perry VH, Jobst KA, King EM, Smith AD: Longitudinal study of inflammatory factors in serum, cerebrospinal fluid, and brain tissue in $\mathrm{Alz}$ heimer disease: interleukin-1beta, interleukin-6, interleukin-1 receptor antagonist, tumor necrosis factor-alpha, the soluble tumor necrosis factor receptors I and II, and alpha1-antichymotrypsin. Alzheimer Dis Assoc Disord 1998;12:215-227.

-11 Pirttila T, Mehta PD, Frey H, Wisniewski HM: Alpha 1-antichymotrypsin and IL-1 beta are not increased in CSF or serum in Alzheimer's disease. Neurobiol Aging 1994; 15:313-317.

-12 Tarkowski E, Blennow K, Wallin A, Tarkowski A: Intracerebral production of tumor necrosis factor-alpha, a local neuroprotective agent, in Alzheimer disease and vascular dementia. J Clin Immunol 1999;19:223230 .
13 Licastro F, Pedrini S, Caputo L, Annoni G, Davis LJ, Ferri C, Casadei V, Grimaldi LM: Increased plasma levels of interleukin-1, interleukin-6 and alpha-1-antichymotrypsin in patients with Alzheimer's disease: peripheral inflammation or signals from the brain? J Neuroimmunol 2000;103:97-102.

14 Teunissen CE, de Vente J, Steinbusch HW, De Bruijn C: Biochemical markers related to Alzheimer's dementia in serum and cerebrospinal fluid. Neurobiol Aging 2002;23:485508 .

15 Weisman D, Hakimian E, Ho GJ: Interleukin, inflammation, and mechanisms of Alzheimer's disease. Vitam Horn 2006;74:505530 .

16 Szczepanik AM, Funes S, Petko W, Ringheim GE: IL-4, IL-10 and IL-13 modulate a beta(1-42)-induced cytokine and chemokine production in primary murine microglia and a human monocyte cell line. J Neuroimmunol 2001;113:49-62.

-17 Ambi F, Reale M, Iarlori C, Salone A, Toma L, Paladini C, De Luca G, Feliciani C, Salvatore M, Salerno RM, Theoharides TC, Conti P, Exton M, Gambi D: Alzheimer patients treated with an ache inhibitor show higher IL-4 and lower IL-1 beta levels and expression in peripheral blood mononuclear cells. J Clin Psychopharmacol 2004;24:314-321. 
18 Ugaresi A, Di Iorio A, Iarlori C, Reale M, De Luca G, Sparvieri E, Michetti A, Conti P, Gambi D, Abate G, Paganelli R: IL-4 in vitro production is upregulated in Alzheimer's disease patients treated with acetylcholinesterase inhibitors. Exp Gerontol 2004;39: 653-657.

-19 Sun YX, Minthon L, Wallmark A, Warkentin S, Blennow K, Janciauskiene S: Inflammatory markers in matched plasma and cerebrospinal fluid from patients with Alzheimer's disease. Dement Geriatr Cogn Disord 2003;16:136-144.

-20 Hampel H, Sunderland T, Kotter HU, Schneider C, Teipel SJ, Padberg F, Dukoff R, Levy J, Moller HJ: Decreased soluble interleukin-6 receptor in cerebrospinal fluid of patients with Alzheimer's disease. Brain Res 1998;780:356-359.

-21 Bonaccorso S, Lin A, Song C, Verkerk R, Kenis G, Bosmans E, Scharpe S, Vandewoude M, Dossche A, Maes M: Serotonin-immune interactions in elderly volunteers and in patients with Alzheimer's disease (DAT): lower plasma tryptophan availability to the brain in the elderly and increased serum interleukin-6 in DAT. Aging (Milano) 1998;10:316323.

-22 Kalman J, Juhasz A, Laird G, Dickens P, Jardanhazy T, Rimanoczy A, Boncz I, ParryJones WL, Janka Z: Serum interleukin-6 levels correlate with the severity of dementia in down syndrome and in Alzheimer's disease. Acta Neurol Scand 1997;96:236-240.

-23 Maes M, DeVos N, Wauters A, Demedts P, Maurits VW, Neels H, Bosmans E, Altamura C, Lin A, Song C, Vandenbroucke M, Scharpe $S$ : Inflammatory markers in younger vs elderly normal volunteers and in patients with Alzheimer's disease. J Psychiatr Res 1999;33: 397-405.

-24 Angelis P, Scharf S, Mander A, Vajda F, Christophidis N: Serum interleukin-6 and interleukin-6 soluble receptor in Alzheimer's disease. Neurosci Lett 1998;244:106108.

$\checkmark 25$ Chao CC, Ala TA, Hu S, Crossley KB, Sherman RE, Peterson PK, Frey WH 2nd: Serum cytokine levels in patients with Alzheimer's disease. Clin Diagn Lab Immunol 1994;1: 433-436.

-26 De Luigi A, Pizzimenti S, Quadri P, Lucca U, Tettamanti M, Fragiacomo C, De Simoni MG: Peripheral inflammatory response in Alzheimer's disease and multiinfarct dementia. Neurobiol Dis 2002;11:308-314.

$\checkmark 27$ Bonotis K, Krikki E, Holeva V, Aggouridaki C, Costa V, Baloyannis S: Systemic immune aberrations in Alzheimer's disease patients. J Neuroimmunol 2008;193:183-187.

-28 Singh VK, Guthikonda P: Circulating cytokines in Alzheimer's disease. J Psychiatr Res 1997;31:657-660.
29 Tarkowski E, Wallin A, Regland B, Blennow K, Tarkowski A: Local and systemic GMCSF increase in Alzheimer's disease and vascular dementia. Acta Neurol Scand 2001;103: 166-174.

30 Rota E, Bellone G, Rocca P, Bergamasco B, Emanuelli G, Ferrero P: Increased intrathecal TGF-beta1, but not IL-12, IFN-gamma and IL-10 levels in Alzheimer's disease patients. Neurol Sci 2006;27:33-39.

31 Angelopoulos P, Agouridaki H, Vaiopoulos H, Siskou E, Doutsou K, Costa V, Baloyiannis SI: Cytokines in Alzheimer's disease and vascular dementia. Int J Neurosci 2008;118: 1659-1672.

32 Baranowska-Bik A, Bik W, Wolinska-Witort E, Martynska L, Chmielowska M, Barcikowska M, Baranowska B: Plasma beta amyloid and cytokine profile in women with Alzheimer's disease. Neuro Endocrinol Lett 2008;29:75-79.

33 Strle K, Zhou JH, Shen WH, Broussard SR, Johnson RW, Freund GG, Dantzer R, Kelley KW: Interleukin-10 in the brain. Crit Rev Immunol 2001;21:427-449.

-34 Speciale L, Calabrese E, Saresella M, Tinelli C, Mariani C, Sanvito L, Longhi R, Ferrante P: Lymphocyte subset patterns and cytokine production in Alzheimer's disease patients. Neurobiol Aging 2007;28:1163-1169.

- 35 Engelborghs S, De Brabander M, De Cree J, D’Hooge R, Geerts H, Verhaegen H, De Deyn PP: Unchanged levels of interleukins, neopterin, interferon-gamma and tumor necrosis factor-alpha in cerebrospinal fluid of patients with dementia of the Alzheimer type. Neurochem Int 1999;34:523-530.

36 Motta M, Imbesi R, Di Rosa M, Stivala F, Malaguarnera L: Altered plasma cytokine levels in Alzheimer's disease: correlation with the disease progression. Immunol Lett 2007;114:46-51.

37 Bruunsgaard H, Andersen-Ranberg K, Jeune B, Pedersen AN, Skinhoj P, Pedersen BK: A high plasma concentration of TNF-alpha is associated with dementia in centenarians. J Gerontol A Biol Sci Med Sci 1999;54:M357M364.

38 Hasegawa Y, Sawada M, Ozaki N, Inagaki T, Suzumura A: Increased soluble tumor necrosis factor receptor levels in the serum of elderly people. Gerontology 2000;46:185188.

39 Cacabelos R, Alvarez XA, Franco-Maside A, Fernandez-Novoa L, Caamano J: Serum tumor necrosis factor (TNF) in Alzheimer's disease and multi-infarct dementia. Methods Find Exp Clin Pharmacol 1994;16:29_ 35
40 Paganelli R, Di Iorio A, Patricelli L, Ripani F, Sparvieri E, Faricelli R, Iarlori C, Porreca E, Di Gioacchino M, Abate G: Proinflammatory cytokines in sera of elderly patients with dementia: levels in vascular injury are higher than those of mild-moderate Alzheimer's disease patients. Exp Gerontol 2002;37:257263.

41 Alvarez XA, Franco A, Fernandez-Novoa L, Cacabelos R: Blood levels of histamine, IL-1 beta, and TNF-alpha in patients with mild to moderate Alzheimer disease. Mol Chem Neuropathol 1996;29:237-252.

-42 Fillit H, Ding WH, Buee L, Kalman J, Altstiel L, Lawlor B, Wolf-Klein G: Elevated circulating tumor necrosis factor levels in Alzheimer's disease. Neurosci Lett 1991;129:318320 .

43 Bermejo P, Martin-Aragon S, Benedi J, Susin C, Felici E, Gil P, Ribera JM, Villar AM: Differences of peripheral inflammatory markers between mild cognitive impairment and Alzheimer's disease. Immunol Lett 2008;117: 198-202.

44 Ray S, Britschgi M, Herbert C, TakedaUchimura Y, Boxer A, Blennow K, Friedman LF, Galasko DR, Jutel M, Karydas A, Kaye JA, Leszek J, Miller BL, Minthon L, Quinn JF, Rabinovici GD, Robinson WH, Sabbagh MN, So YT, Sparks DL, Tabaton M, Tinklenberg J, Yesavage JA, Tibshirani R, WyssCoray T: Classification and prediction of clinical Alzheimer's diagnosis based on plasma signaling proteins. Nat Med 2007;13: 1359-1362.

-45 Galimberti D, Schoonenboom N, Scarpini E, Scheltens P: Chemokines in serum and cerebrospinal fluid of Alzheimer's disease patients. Ann Neurol 2003;53:547-548.

46 Blasko I, Lederer W, Oberbauer H, Walch T, Kemmler G, Hinterhuber H, Marksteiner J, Humpel C: Measurement of thirteen biological markers in CSF of patients with Alzheimer's disease and other dementias. Dement Geriatr Cogn Disord 2006;21:9-15.

47 Lee KS, Chung JH, Lee KH, Shin MJ, Oh BH, Hong CH: Bioplex analysis of plasma cytokines in Alzheimer's disease and mild cognitive impairment. Immunol Lett 2008;121: 105-109.

48 Kim TS, Lim HK, Lee JY, Kim DJ, Park S, Lee C, Lee CU: Changes in the levels of plasma soluble fractalkine in patients with mild cognitive impairment and Alzheimer's disease. Neurosci Lett 2008;436:196-200.

49 Quan N, Herkenham M: Connecting cytokines and brain: a review of current issues. Histol Histopathol 2002;17:273-288.

50 Fulton RJ, McDade RL, Smith PL, Kienker LJ, Kettman JR Jr: Advanced multiplexed analysis with the FlowMetrix system. Clin Chem 1997;43:1749-1756. 